\title{
Inhibition of Cytokine-Induced Fractalkine Production by Bacterial Invasion of Human-Dermal Fibroblasts
}

\author{
Olivier Luc Fahy, Nicholas John Coates, and Shaun Reuss McColl \\ Chemokine Biology Laboratory, Department of Molecular Biosciences, The University of Adelaide, Australia.
}

\begin{abstract}
SUMMARY: Fractalkine (FKN/CX $\left.{ }_{3} \mathrm{CL} 1\right)$ is an atypical chemokine, for which a major biological function has not yet emerged. However, recent data suggest a role in immune responses in the skin. In this study, we analyzed fractalkine (FKN) secretion by human-dermal fibroblasts after exposure to pro-inflammatory cytokines or to invasive and noninvasive strains of Escherichia coli. Incubation of fibroblasts with TNF- $\alpha$ and IL-1 $\beta$ induced a delayed expression of soluble FKN, compared with the rapid secretion of other chemokines including IL-8 (CXCL8), monocyte chemotactic protein-1 (CCL2), and RANTES (regulated upon activation, normal T cell expressed and secreted; CCL5). TNF- $\alpha$ and IFN- $\gamma$ gamma were more potent at inducing FKN secretion than was $\mathrm{IL}-1 \beta$. Very little FKN was detected on the cell surface. FKN was not detected after incubation with the bacteria, regardless of the strain used. In contrast, both invasive and noninvasive $E$. coli triggered the release of IL-8 and monocyte chemotactic protein-1 in a dose-response manner, whereas RANTES was produced only in response to the invasive strain. Finally, incubation of fibroblasts with the invasive strain of $E$. coli inhibited TNF- $\alpha$ - and IFN- $\gamma$-induced production of FKN. These results demonstrate for the first time that human-dermal fibroblasts express FKN, and that the characteristics of FKN secretion are distinct from those of other chemokines produced by these cells during immune responses in the dermis. In addition, our data indicate that bacterial invasion of dermal fibroblasts actively modulates FKN expression. (Lab Invest 2003, 83:721-730).
\end{abstract}

$C$ hemokines are small proteins originally described as chemoattractant cytokines that regulate leukocyte trafficking (Gale and McColl, 1999). In addition to their role as chemotactic factors, it is becoming increasingly evident that chemokines also mediate structural cell proliferation and angiogenesis and may therefore play a crucial role in wound repair (Rennekampff et al, 2000; Tuschil et al, 1992). The chemokines can be divided into two categories based on functional expression. The constitutive chemokines are expressed mainly in secondary lymphoid organs and are largely involved in lymphocyte homing/homeostasis. The inducible chemokines are expressed on stimulation and play critical roles in inflammatory responses by controlling the trafficking of effector leukocytes to sites of inflammation and infection. To date, the chemokine gene superfamily numbers over 40 , and a major challenge is to determine the biological function of each of these members.

Among the chemokines, fractalkine (FKN/CX $\left.{ }_{3} \mathrm{CL} 1\right)$ is highly unusual. Unlike the majority of chemokines that are small (approximately $8 \mathrm{kd}$ ) and exclusively secreted, FKN is a large molecule of 373 amino acids and contains an $\mathrm{N}$-terminal chemokine domain, a mucin-like stalk that is heavily $\mathrm{O}$-glycosylated, a trans-

DOI: 10.1097/01.LAB.0000069518.49544.B8

Received February 11, 2003.

This study was supported by a grant from the National Health and Medical Research Council of Australia.

Address reprint requests to: Associate Professor Shaun R. McColl, Head, Chemokine Biology Laboratory, Department of Molecular Biosciences, Adelaide University, North Terrace Campus, South Australia 5005, Australia.E-mail: shaun.mccoll@adelaide.edu.au membrane domain, and an intracellular domain. Several in vitro studies have indicated that FKN displays a unique dual function as an adhesion molecule and a chemotactic factor, depending on its form as a membrane-anchored or a soluble protein, respectively (Bazan et al, 1997). Recent data show that the relative levels of membrane-bound versus secreted $\mathrm{FKN}$ is dependent on the activity of the TNF- $\alpha$ converting enzyme (TACE, ADAM17) that is responsible for the cleavage of FKN from the surface of activated cells (Tsou et al, 2001). It may be postulated that the ability of FKN to function as an adhesion molecule would depend on relatively low levels of TACE activity, whereas higher levels of TACE activity would allow the soluble chemotactic factor activity of FKN to predominate. More recently, FKN expression has been observed in peripheral tissues and documented on the surface of cultured epithelial cells, endothelial cells, and smooth-muscle cells in response to TNF- $\alpha$, IL-1 $\beta$, and IFN- $\gamma$ (Ludwig et al, 2002; Muehlhoefer et al, 2000; Yoshida et al, 2001). However, to date the level of FKN secreted by cells has not yet been quantitatively determined. This an important issue because it is in the secreted form that FKN is postulated to act as a chemoattractant for target cells such as mononuclear phagocytes, $\mathrm{CD}^{+} \mathrm{T}$ cells, and natural killer cells (Imai et al, 1997).

It is increasingly recognized that dermal fibroblasts, a major cellular constituent of dermal connective tissue, have an important role in immune defense. On stimulation, for example by bacteria that may have penetrated the dermis, fibroblasts produce a number of cytokines and chemokines, thereby participating in the development and resolution of inflammation and in 
the subsequent tissue repair (Gillitzer and Goebeler, 2001). Whether fibroblasts express FKN is presently unknown. In this study, we investigated the capacity of human-dermal fibroblasts to release FKN in response to bacteria and pro-inflammatory cytokines and compared this with the production of several other chemokines. In addition, we investigated the effects of bacterial invasion on this process using a genetically engineered invasive strain of Escherichia coli and its wild-type counterpart as a control.

\section{Results}

\section{TNF- $\alpha$ and IL-1 $\beta$ Induce the Release of Soluble FKN by Human-Dermal Fibroblasts}

Dermal fibroblasts isolated from human foreskin were cultured to $80 \%$ confluence before being exposed to TNF- $\alpha$ or IL-1 $\beta$. In a time-course study of FKN expression using a sandwich ELISA assay, soluble FKN was found to be released by the dermal fibroblasts after a delay of 48 hours poststimulation with the inflammatory cytokines TNF- $\alpha(100 \mathrm{ng} / \mathrm{ml})$ or $\mathrm{IL}-1 \beta(5 \mathrm{ng} / \mathrm{ml})$. The levels of FKN measured in the supernatants after 48 and 72 hours of exposure to TNF- $\alpha$ were significantly higher than the respective PBS controls (Fig. 1A). Levels of FKN after IL-1 $\beta$ exposure also were higher than the PBS controls at 48 hours, although this was not statistically significant, and concentrations after 72-hour culture had returned to control levels.

To assess the intracellular levels of FKN, fibroblasts were lysed and cell debris was removed by centrifugation. The time-course profile of intracellular levels of FKN after TNF- $\alpha$ stimulation was similar to that observed in the supernatants, with a significant increase at 48 hours compared with PBS (Fig. 1B). No intracellular FKN was detected after IL-1 $\beta$ stimulation regardless of the time point tested.

In a parallel set of experiments the effect of dose of TNF- $\alpha$ and IL- $1 \beta$, and IFN- $\gamma$ on the production of FKN in the supernatants was evaluated. The results showed that $100 \mathrm{ng} / \mathrm{ml}$ of TNF- $\alpha, 50 \mathrm{ng} / \mathrm{ml}$ of IFN- $\gamma$, and $5 \mathrm{ng} / \mathrm{ml}$ of IL-1 $\beta$ induced maximal release of FKN after 48-hour culture (Fig. 1C). Higher doses seemed equally or less efficient for TNF- $\alpha$ and IL-1 $\beta$, respectively.

Secretion of the chemokines, IL-8, monocyte chemotactic protein-1 (MCP-1), and RANTES, by dermal fibroblasts also was assessed by ELISA in the supernatants. After stimulation with TNF- $\alpha(100 \mathrm{ng} / \mathrm{ml})$, the level of all three chemokines was increased (Fig. 2). This effect was less pronounced when the fibroblasts were stimulated with IL-1 $\beta(5 \mathrm{ng} / \mathrm{ml})$, although the level of all three chemokines clearly increased compared with controls. Of note, and in contrast to that observed with FKN, maximal expression was observed much more rapidly. High levels of IL-8 were measured as early as 2 hours after stimulation (Fig. 2A), and maximal levels of MCP-1 and RANTES were observed at 24 hours after stimulation (Fig. 2, B and C). A stimulatory effect of the two inflammatory cytokines on the expression of IL-8, MCP-1, and RANTES also was observed at the mRNA level (data not shown).
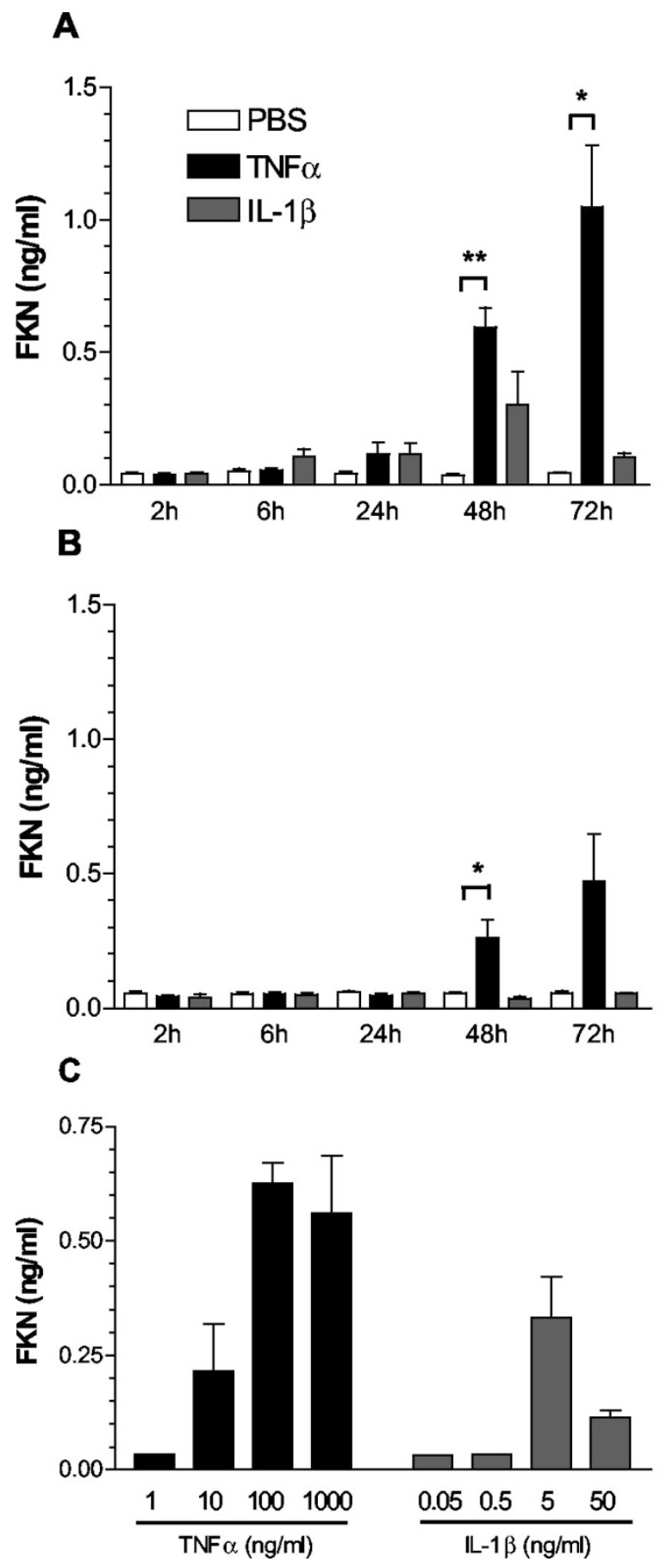

Figure 1.

Kinetics and dose-response of the production of FKN by human-dermal fibroblasts. Supernatants (A) and lysates (B) from cells incubated with PBS control, TNF- $\alpha(100 \mathrm{ng} / \mathrm{ml})$, or IL-1 $\beta(5 \mathrm{ng} / \mathrm{ml})$ were collected at several time points and analyzed for FKN levels by ELISA ( $n \geq 6$ for culture supernatants, $n \geq 3$ for lysates). ${ }^{\star} p<0.05 ;{ }^{* \star} p<0.0001$ compared with control values. $\mathrm{C}$, Cells also were incubated with increasing doses of TNF- $\alpha$, IL-1 $\beta$, or IFN- $\gamma$ for 48 hours and supernatants collected for measurement of FKN levels ( $n=$ 4). All results are expressed as mean \pm SEM.

\section{RT-PCR Analysis of FKN Expression by Human-Dermal Fibroblasts}

FKN mRNA expression in dermal fibroblasts incubated with PBS control, TNF- $\alpha(100 \mathrm{ng} / \mathrm{ml})$, or IL- $1 \beta$ (5 


\section{A}
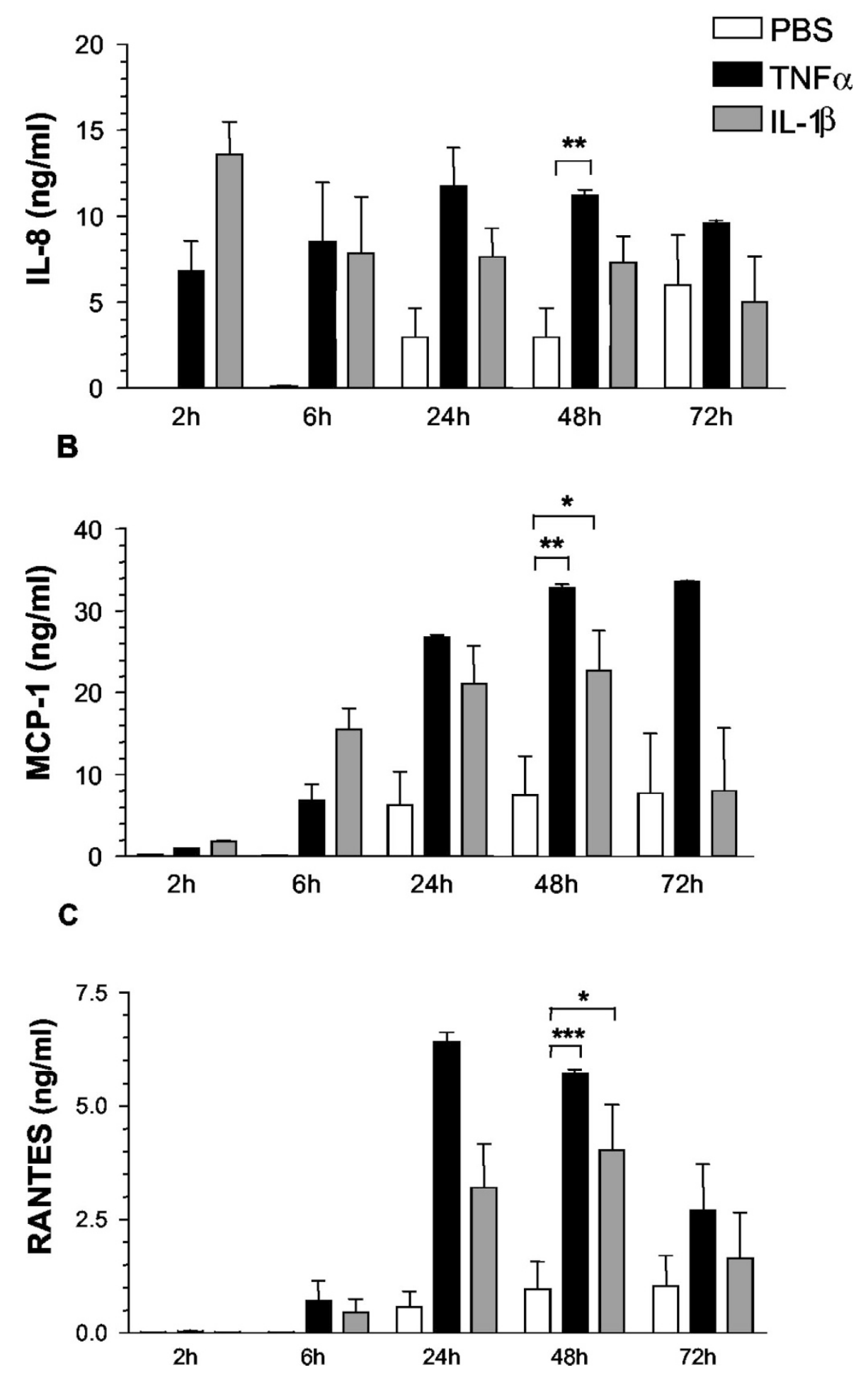

Figure 2.

Production of IL-8, MCP-1, and RANTES by human-dermal fibroblasts. Supernatants from cells incubated with PBS control, TNF- $\alpha(100 \mathrm{ng} / \mathrm{ml})$, or IL- $1 \beta(5 \mathrm{ng} / \mathrm{ml})$ were collected at several time points and analyzed by ELISA for IL-8 (A), MCP-1 (B), and RANTES (C). $n \geq 6$; ${ }^{\star} p<0.05 ;{ }^{\star \star} p<0.001 ;{ }^{* \star \star} p<0.0001$ compared with control values. The results are expressed as mean \pm SEM.

$\mathrm{ng} / \mathrm{ml}$ ) was examined by RT-PCR. As shown in Figure $3 \mathrm{~A}, \mathrm{FKN}$ mRNA levels were markedly increased when the fibroblasts were incubated for 48 hours with $\operatorname{TNF}-\alpha$, and an increase of lower magnitude was observed when the cells were incubated with IL-1 $\beta$. When calculated as a percentage of the expression of the housekeeping gene, glyceraldehyde-3-phosphate dehydrogenase (GAPDH), incubation with TNF- $\alpha$ was 
A

\section{PBS TNF $\alpha$ IL-1 $\beta$}

\section{GAPDH}

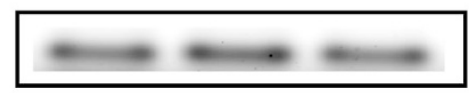

FKN 48h

B

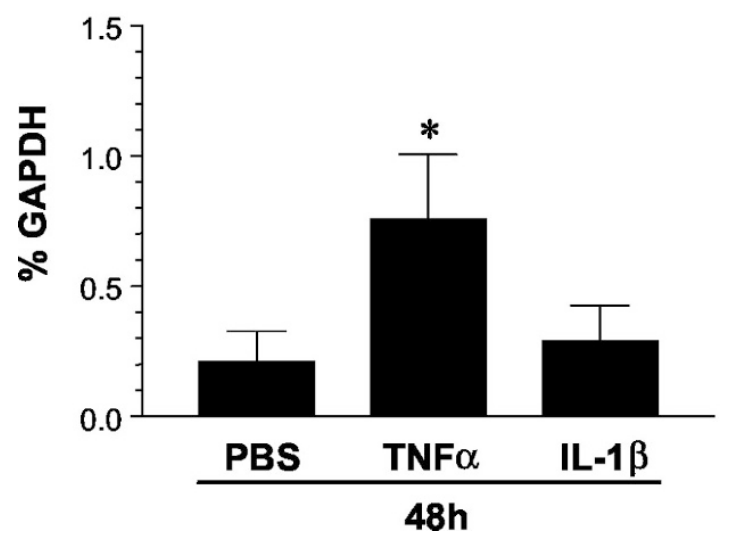

Figure 3.

Upregulation of FKN steady-state mRNA after incubation of the fibroblasts with TNF- $\alpha$ and IL- $1 \beta$. Fibroblasts were cultured for 48 hours, total RNA was extracted, reverse-transcribed, and used in PCR reactions with GAPDH- and FKN-specific primers. A, Representative agarose gel of GAPDH and FKN mRNA amplification. B, Densitometric analysis of four independent experiments. Data are presented as the ratio of band intensity relative for GAPDH. ${ }^{*} p<0.05$ versus control.

found to induce a statistically significant $259 \%$ increase of FKN mRNA expression compared with the PBS controls, whereas incubation with IL-1 $\beta$ induced a $38 \%$ increase, which was not statistically significant (Fig. 3B). FKN mRNA at the 24-hour time point was highly variable, with very weak or, most commonly, no expression of FKN mRNA detected.

\section{TNF- $\alpha$ and IL-1 Enhance the Expression of FKN on the Membrane of Human-Dermal Fibroblasts}

The ability of TNF- $\alpha$ and IL- $1 \beta$ to induce expression of FKN on the cell surface was examined next. Initial studies failed to reproducibly demonstrate FKN expression in the cell surface in resting cells or in response to TNF- $\alpha$ or IL-1 $\beta$ (data not shown). However, the use of a potent broad-spectrum hydroxamate inhibitor of matrix metalloproteinase during the incubation allowed us to reproducibly measure FKN expression on the cell membrane. Fibroblasts cultured for 48 hours were processed for flow cytometric analysis of $\mathrm{FKN}$, using a phycoerythrin-conjugated anti-FKN antibody (Ab). Cell viability, as assessed by Trypan Blue exclusion tests, was superior to 95\% after 48 hours in all conditions. Compared with control cells, the peak corresponding to the fibroblasts incubated with IL-1 $\beta$ displayed a moderate shift to higher intensity of fluorescence. When incubated with TNF- $\alpha$, that shift to higher fluorescence intensity was more pronounced, demonstrating a stronger increase in the expression of FKN on the membrane of the fibroblasts (Fig. 4). Of note, when using the matrix metalloproteinase inhibitor, the release of FKN into the supernatants in response to TNF- $\alpha$ and IL-1 $\beta$ was reduced to a level similar to the PBS control (data not shown).

\section{Bacteria Do Not Induce FKN Production in Dermal Fibroblasts}

The next series of experiments were designed to evaluate the ability of invasive and noninvasive bacteria to induce FKN expression by dermal fibroblasts. To specifically address the influence of bacterial invasion, E. coli, a naturally noninvasive, Gram-negative bacterium was transformed with a plasmid encoding the invasin gene of Yersinia pseudotuberculosis. However, because the capacity of the wild-type and invasive strains of $E$. coli to infect human-dermal fibroblasts had not been examined, preliminary experiments were conducted to examine these parameters. Increasing concentrations of bacteria were added to the culture medium of established human-dermal fibroblast monolayers. After 1 hour, the monolayers were washed several times (to remove unbound bacteria) and the cells were stained with DAPI (4',6-diamidino2-phenylindole), a DNA-specific probe that forms a fluorescent complex by attaching to the minor groove of A-T rich sequences of DNA, to allow visualization of both bacterial and eukaryotic DNA. The wild-type $E$. coli strain ( $E$. coli ${ }^{\mathrm{wt}}$ ) was not able to enter the fibroblasts, irrespective of the concentration used. Even at the highest concentration $\left(5 \times 10^{7}\right.$ colony-forming unit

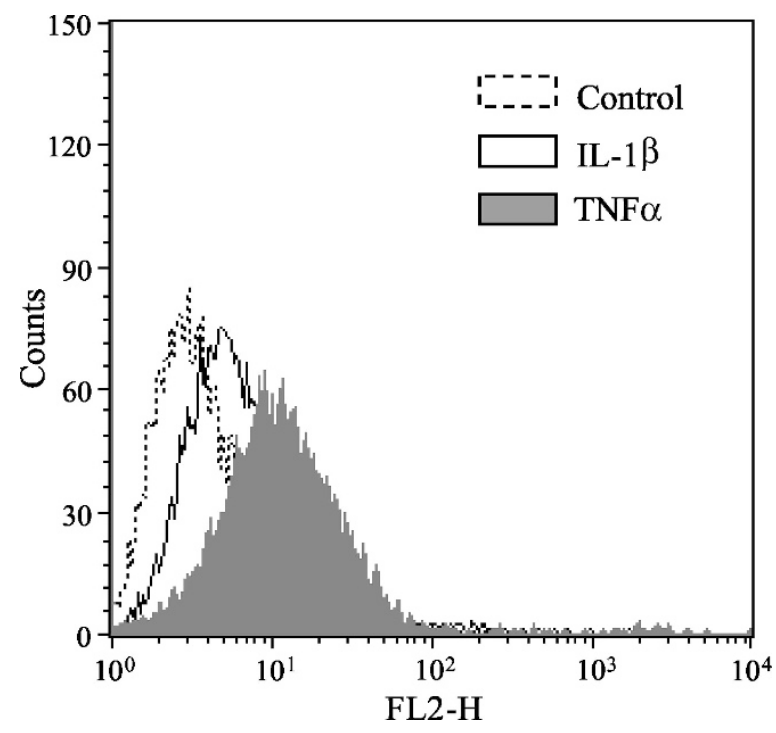

Figure 4.

Flow-cytometric analysis of FKN surface expression on human-dermal fibroblasts. Cells were incubated for 48 hours with GM6001, an inhibitor of matrix metalloproteinase $(50 \mu \mathrm{m})$ and with PBS control, TNF- $\alpha(100 \mathrm{ng} / \mathrm{ml})$, or IL- $1 \beta$ $(5 \mathrm{ng} / \mathrm{ml})$. Cells then were collected, labeled with a specific anti-FKN $A b$, and analyzed by flow cytometry. Shown are histograms obtained in one experiment that is representative three. Dotted line, PBS control. Solid line, IL-1 $\beta$. Filled histogram, TNF- $\alpha$. FL2-H, Fluorescence. 
$[\mathrm{cfu}] / \mathrm{ml}$ ) the staining revealed only a few bacteria left after washing, appearing randomly in the microscope fields (Fig. 5). In contrast, the transformed strain of $E$. coli (invasive) (E. coli ${ }^{\text {iny }}$ ) was clearly capable of invading the fibroblasts. After the washing steps, most of these bacteria were still associated with the fibroblasts. In addition, the infection was clearly dosedependent (Fig. 5). Under conditions of incubation, cell viability as assessed by Trypan Blue exclusion tests was superior to $97 \%$ after 24 hours and to $95 \%$ after 48 hours of culture.

The ability of the invasive and wild-type strains of $E$. coli to trigger the production of FKN by human-dermal fibroblasts was then investigated. Monolayers of fibroblasts were exposed to $E$. coli ${ }^{\mathrm{wt}}$ or $E$. coli ${ }^{\mathrm{inv}}$ for 1 hour. The cells were then washed and fresh medium was added. The medium was supplemented with antibiotics to maintain a constant dose of bacteria by preventing the multiplication of bacteria in the medium over the subsequent 48-hour period. Neither $E$. coli ${ }^{\text {wt }}$ nor $E$. colinv $^{\text {inv }}$ triggered the release of FKN into the supernatants, with levels similar to the PBS control (Fig. 6A). For comparison, TNF- $\alpha$ - or IFN- $\gamma$-induced release of FKN also are shown, with FKN levels significantly higher than for the control. Interestingly, TNF- $\alpha$ (100 $\mathrm{ng} / \mathrm{ml})$ and IFN- $\gamma(50 \mathrm{ng} / \mathrm{ml})$ were found to have an
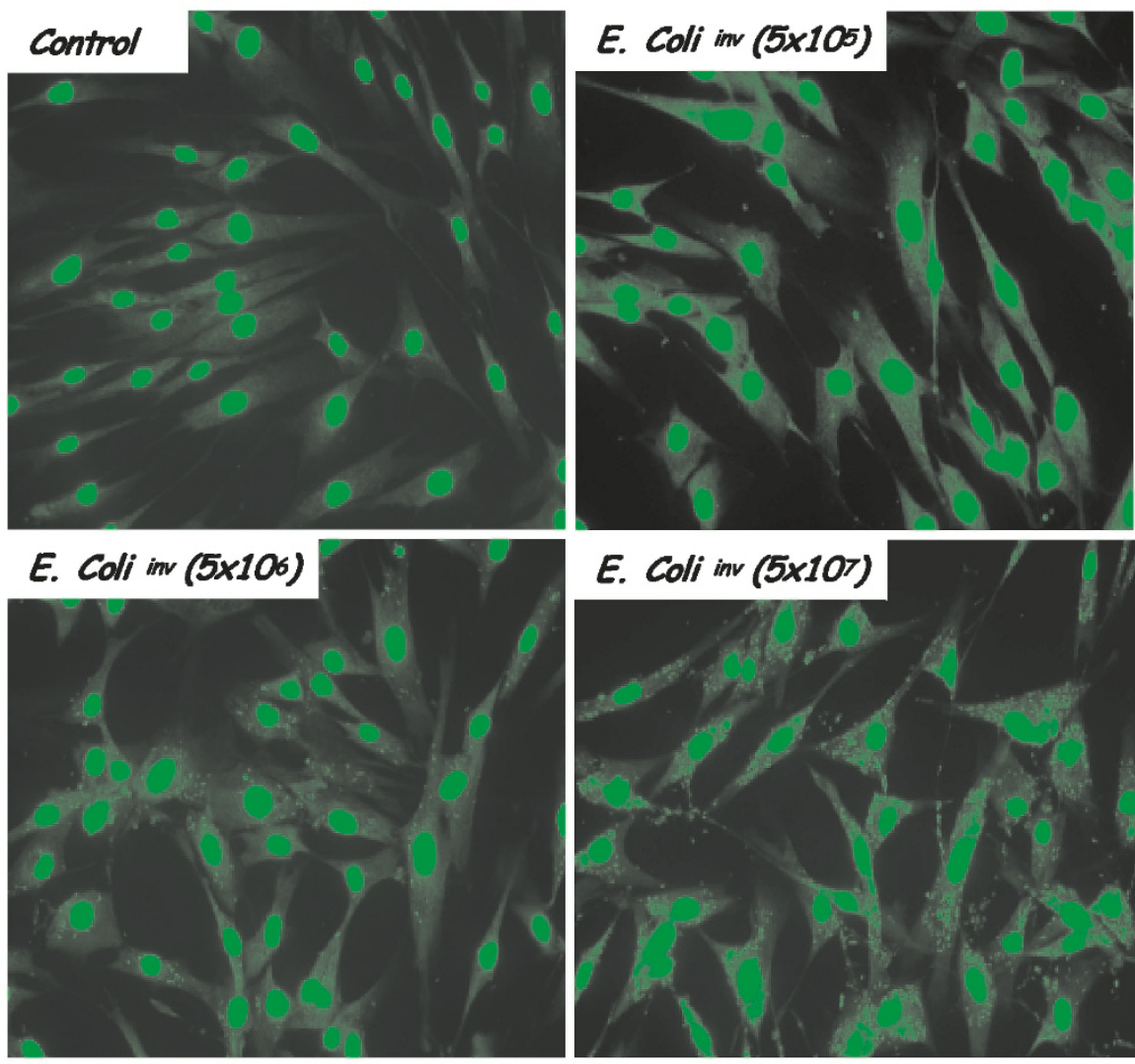

\section{E. Coli inv $(5 \times 107)$}

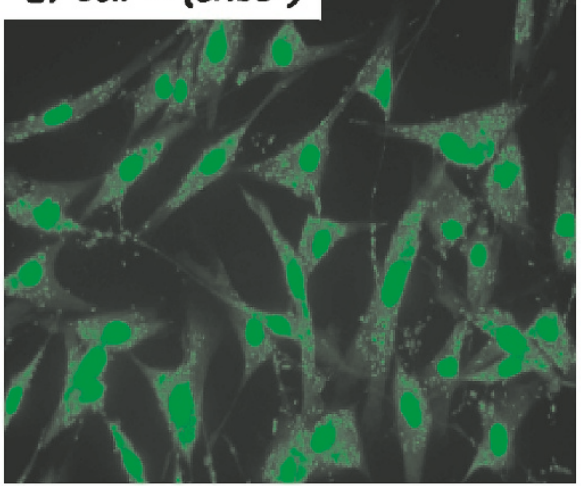

\section{E. Coli wt $(5 \times 107)$}

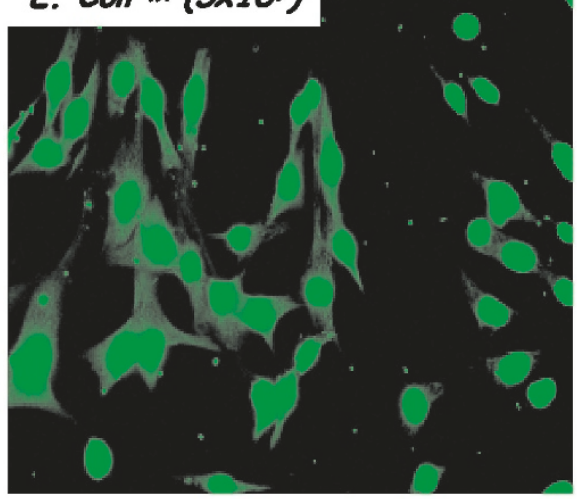

Figure 5.

Visualization of bacterial infection. Human-dermal fibroblasts were exposed to various doses of $E$. coli ${ }^{\text {wt }}$ and $E$. colinv $\left(5 \times 10^{5}, 5 \times 10^{6}\right.$, and $5 \times 10^{7}$ bacteria per $2.5 \times 10^{5}$ fibroblasts). Control, no bacteria. After incubation of the fibroblast layer for 1 hour with the bacteria, cells were washed and stained with DAPI before mounting and visualization with a fluorescence microscope. Eukaryotic nuclei appear as large and brightly fluorescent oval-shaped disks. Bacteria appear as small fluorescent points. 
A

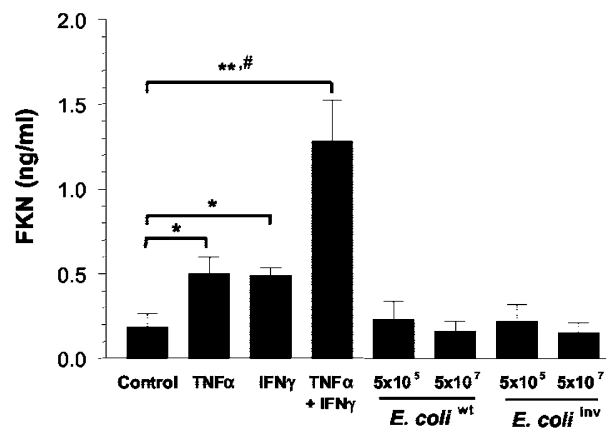

C

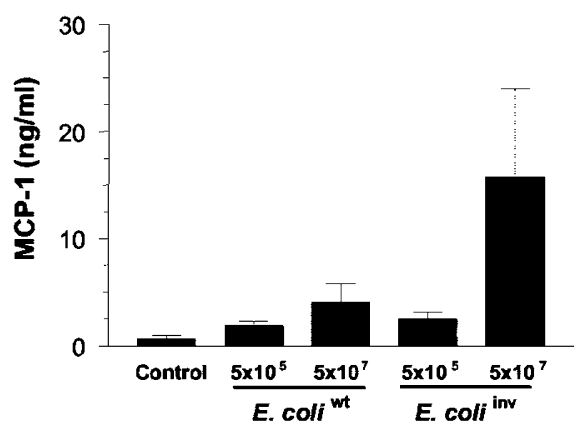

B

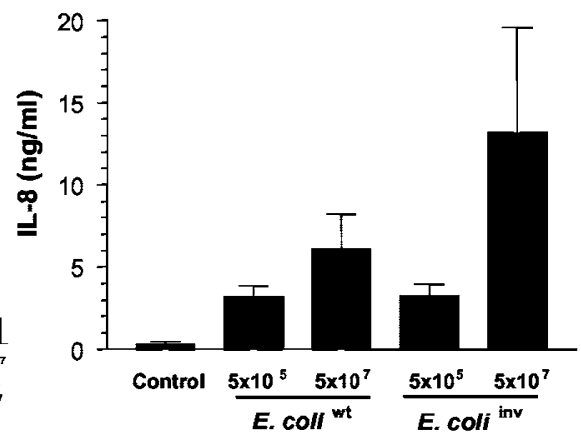

D

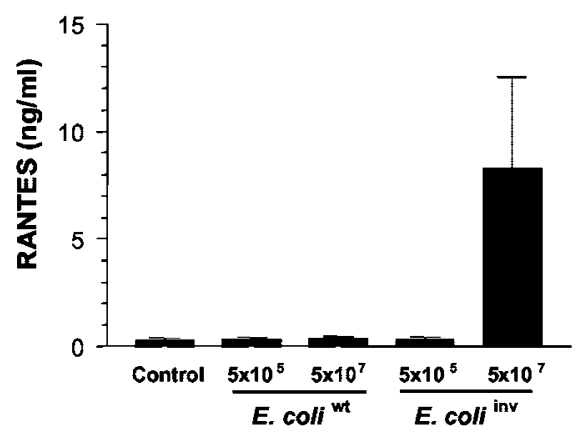

Figure 6.

Induction of chemokine expression in fibroblasts by bacteria. Human-dermal fibroblasts were exposed to low $\left(5 \times 10^{5}\right)$ or high $\left(5 \times 10^{7}\right)$ doses of $E$. colit or $E$. coli inv for 1 hour. Plates then were washed and fresh medium supplemented with L-glutamine and penicillin and gentamicin was added. After 48-hour incubation, supernatants were collected and assessed for FKN (A), IL-8 (B), MCP-1 (C), and RANTES (D) levels by ELISA. $(n=4-6)$. ${ }^{*} p<0.05$ versus control; ${ }^{* *} p<0.005$ versus control; $\# p<0.05$ versus TNF- $\alpha(100 \mathrm{ng} / \mathrm{ml})$ and versus IFN- $\gamma(50 \mathrm{ng} / \mathrm{ml})$. Control, no bacteria or cytokine. All results are expressed as mean \pm SEM.

additive effect on the production of FKN by the fibroblasts.

In contrast, incubation of the cells with $E$. coliwt or $E$. coli ${ }^{\text {inv }}$ triggered the release of IL-8. Irrespective of the strain, the low dose of bacteria $\left(5 \times 10^{5} \mathrm{cfu} / \mathrm{ml}\right)$ induced a similar level of IL-8 production, which was significantly higher than in the supernatants of the control cells cultured without bacteria (Fig. 6B). Exposure to high doses of bacteria $\left(5 \times 10^{7} \mathrm{cfu} / \mathrm{ml}\right)$ resulted in a higher level of IL-8 production, with the $E$. colinv strain being the more potent of the two. A similar pattern was observed for the release of MCP-1 after bacterial exposure, with levels for $\mathrm{MCP}-1$ similar to those obtained for IL-8 (Fig. 6C). Again, the highest dose of $E$. coli ${ }^{\text {inv }}$ proved the most potent condition with respect to chemokine production by the fibroblasts. In contrast, a different pattern was observed in the case of RANTES production. E. coli ${ }^{\text {wt }}$ was not able to induce the release of RANTES, even when at the highest concentration (Fig. 6D). The low dose of $E$. colinv $^{\text {inv }}$ also was ineffective, with levels of RANTES comparable to PBS control values. In contrast, the high dose of $E$. coli ${ }^{\text {inv }}$ triggered a strong release of RANTES in the supernatants, with levels similar to those observed for IL-8 and MCP-1.

\section{A High Level of Bacterial Invasion Inhibits the Production of FKN Induced by TNF- $\alpha$ and IFN- $\gamma$}

The effects of bacterial exposure on FKN production by human-dermal fibroblasts were further examined by testing the hypothesis that bacteria may actively inhibit FKN expression. If this hypothesis were correct, then it was possible that TNF- $\alpha-$ and TNF- $\alpha+$ IFN- $\gamma-$ induced release of FKN by fibroblasts may be inhibited by co-incubation with the bacteria. Therefore, fibroblasts were incubated with either TNF- $\alpha$ or TNF- $\alpha$ and IFN- $\gamma$ in the presence or absence of different doses of invasive or noninvasive $E$. coli. The supernatants were collected after 48-hour culture and analyzed by ELISA. As shown in Figure 7, co-incubation of the fibroblasts with TNF- $\alpha$ and the high dose of $E$. coli ${ }^{\text {inv }}$ significantly inhibited the release of FKN in the culture supernatants. Co-incubation with TNF- $\alpha$ and E. coliwt also reduced $\mathrm{FKN}$ release into the supernatants, although this decrease did not achieve statistical significance. Incubation with $E$. coli ${ }^{\text {wt }}$ or with the low dose of $E$. colinv had no effect on production of FKN in response to TNF- $\alpha+$ IFN- $\gamma$. However, co-incubation with a high dose of the invasive $E$. coli resulted in a statistically significant inhibition of the TNF- $\alpha+$ IFN- $\gamma$-induced production of FKN. We also attempted to observe the effect of these treatments on steady-state mRNA for FKN. However, we could not consistently isolate highquality RNA from dermal fibroblasts that had been incubated with $E$. colinv (data not shown).

\section{Discussion}

In this study, we examined the ability of human-dermal fibroblasts to secrete the atypical chemokine FKN in 


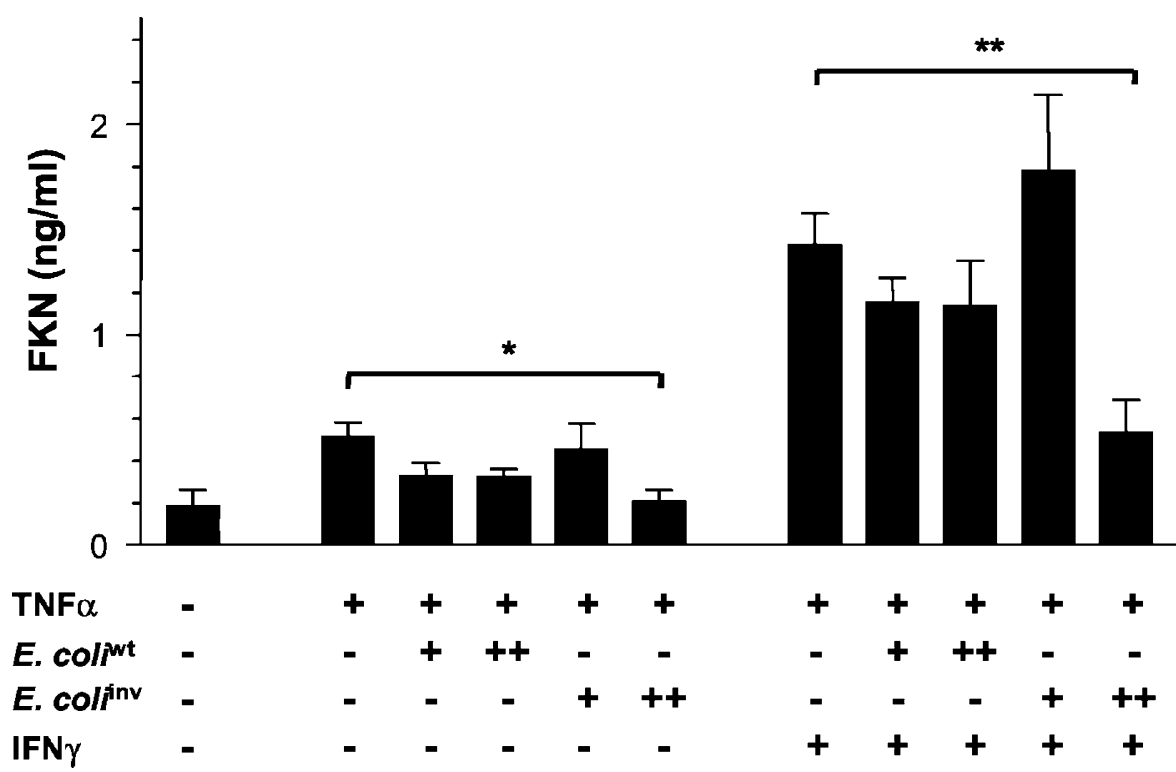

Figure 7.

Bacterial inhibition of the TNF- $\alpha+$ IFN- $\gamma$-induced production of FKN. Human-dermal fibroblasts were incubated with TNF- $\alpha(100 \mathrm{ng} / \mathrm{ml})$ or with TNF- $\alpha+$ IFN- $\gamma(100$ $\mathrm{ng} / \mathrm{ml}$ and $50 \mathrm{ng} / \mathrm{ml}$, respectively) and $5 \times 10^{5} \mathrm{cfu} / \mathrm{ml}(+)$ or $5 \times 10^{7} \mathrm{cfu} / \mathrm{ml}(++)$. E. coll $l^{\mathrm{wt}}$ or $E$. coli ${ }^{\text {ivv }}$ were added to the culture for 1 hour. Plates then were washed and fresh medium supplemented with L-glutamine and penicillin and gentamicin was added. After 48-hour incubation, supernatants were collected and assessed for FKN level by ELISA $(n=6)$. ${ }^{\star} p<0.05$ versus TNF- $\alpha$; ${ }^{* *} p<0.005$ versus TNF- $\alpha+$ IFN- $\gamma$. All results are expressed as mean \pm SEM.

response to pro-inflammatory cytokines and bacteria. Our results clearly demonstrated that dermal fibroblasts secrete relatively low levels of FKN compared with chemokines, such as IL-8, MCP-1, and RANTES, and that FKN production is comparatively slow. In addition, unlike the case with the other inflammatory chemokines examined, dermal fibroblasts failed to up-regulate FKN expression on exposure of the cells to bacteria.

FKN was not detected in dermal fibroblast cell lysates or supernatants unless the cells were stimulated with $\mathrm{TNF}-\alpha$, and to a lesser extent, IL-1 $\beta$. IL-1 $\beta$ exerted only a transient stimulatory effect at 48 hours, whereas TNF- $\alpha$ exerted a sustained effect with levels of secreted FKN continuing to increase even after 72 hours of culture. The profile of intracellular FKN induced by TNF- $\alpha$ was identical to the profile of soluble secreted FKN, whereas no intracellular FKN could be detected after IL-1 $\beta$ stimulation. This relative potency of TNF- $\alpha$ and IL- $1 \beta$ is in accordance with the results of previous studies assessing FKN mRNA levels and surface expression by other cell types including epithelial and endothelial cells (Ludwig et al, 2002; Muehlhoefer et al, 2000; Yoshida et al, 2001). However, in contrast to that shown in other cell types (Lucas et al, 2001; Muehlhoefer et al, 2000), FKN was not detected on the surface of dermal fibroblasts unless the cells were stimulated with TNF- $\alpha$ (and to a lesser extent $\mathrm{IL}-1 \beta)$ in the presence of the TACE inhibitor, GM6001. This indicates that the major biological form of FKN produced by fibroblasts is the soluble form, probably caused by high levels of TACE expression (data not shown). This finding is of interest when considering the proposed dual function of FKN as a cell surface adhesion molecule and a secreted chemotactic factor. Immunohistological studies have determined that the membrane-bound form of FKN is highly expressed in endothelial cells in the skin under inflammatory conditions likely to involve production of TNF- $\alpha$ and IL- $1 \beta$, and associated with an accumulation of $\mathrm{T}$ lymphocytes in the skin (Raychaudhuri et al, 2001). Although production of membrane-bound FKN may mediate T-lymphocyte adherence to the blood vessels (Fong et al, 1998), facilitating extravasation of T cells, production of soluble, chemotactic FKN by dermal fibroblasts may contribute to the localization of FKN receptorbearing cells, including lymphocytes within the tissue after extravasation.

Compared with other chemokines, FKN secretion by dermal fibroblasts after stimulation with TNF- $\alpha$ was relatively slow. Detectable FKN production by dermal fibroblasts only occurred after 48 hours of stimulation, a delay that is in contrast with the very rapid release of IL-8 and MCP-1, both of which were secreted at significant levels after only 2 and 6 hours of stimulation, respectively (data not shown). Although RANTES secretion was not statistically greater than control levels until 24 hours of stimulation, it still peaked more than 24 hours earlier than when FKN was first detected. These data are similar to those previously observed for IL-8, MCP-1, and RANTES production in synovial fibroblasts (Hachicha et al, 1993; Rathanaswami et al, 1993a, 1993b). This delay in FKN expression also was observed at the mRNA level, with no consistently detectable signal before the 48-hour time point (data not shown). Delayed production of the soluble chemotactic molecule by dermal fibroblasts under inflammatory conditions may indicate that FKN is involved in the late rather than the early phase of the inflammation in the dermis, and combined with recent data indicating a potential role for FKN in angiogenesis (Volin et al, 2001), suggests that FKN could play an 
important role in wound repair in skin. This delay in the production of FKN also suggests that additional intermediate molecules secreted by the fibroblasts, such as member of the TGF family or endogenous TNF- $\alpha$, may be involved in the overall regulation of FKN production.

Having demonstrated that human-dermal fibroblasts secrete FKN when stimulated with inflammatory cytokines, we investigated the ability of bacteria to stimulate FKN production by these cells. In particular, we sought to determine whether bacterial invasion alters FKN expression. To avoid the myriad of differences with respect to virulence factors that exist between different bacterial species, we compared two strains of $E$. coli that were identical except for invasive capacity. Wild-type $E$. coli is naturally noninvasive toward eukaryotic targets. An invasive strain was therefore engineered by transforming $E$. coli with a plasmid containing the cDNA encoding the invasin protein of Y. pseudotuberculosis (Isberg et al, 1987; Rosenshine et al, 1992). Surprisingly, no FKN was produced by the fibroblasts after exposure to either strain of the bacteria. This complete lack of effect of the bacteria on FKN expression was unexpected, in view of the results obtained when stimulating the fibroblasts with TNF- $\alpha$, or with a combination of TNF- $\alpha$ and IFN- $\gamma$, both of which will be present in the dermal environment during bacterial infection. Among the chemokines investigated in this study, FKN was the only gene not stimulated after exposure of dermal fibroblasts to bacteria. IL-8 and MCP-1 production was dose-dependently increased in response to both invasive and noninvasive bacteria, although the pattern of RANTES expression was different, with only the higher dose of invasive bacteria inducing its expression.

The observation that bacteria failed to stimulate FKN expression in dermal fibroblasts raised the possibility that exposure of the cells to bacteria may actively interfere with FKN production induced by host-defense responses such as TNF- $\alpha$ and IFN- $\gamma$. We have already established a precedent for this in neutrophils, where TNF- $\alpha$-induced MIP- $1 \alpha$ expression is inhibited when neutrophils phagocytose certain microorganisms (Hachicha et al, 1998). In this study, we found that the invasive strain of $E$. coli had a marked inhibitory effect on the TNF- $\alpha$ - as well as TNF- $\alpha$ and IFN- $\gamma$-induced FKN production, whereas the noninvasive strain of $E$ coli was without effect. The ability of invasive bacteria to prevent cytokine-induced FKN expression in dermal fibroblasts raises the question of whether this would confer a selective advantage on intracellular bacteria, or whether it is a host defense mechanism. Although to date no clear biologic role has been established for FKN or its receptor, $\mathrm{CX}_{3} \mathrm{CR} 1$, a picture is beginning to emerge. $\mathrm{CX}_{3} \mathrm{CR} 1$ is expressed on mononuclear phagocytes, CD8 ${ }^{+} \mathrm{T}$ cells, and natural killer cells (Imai et al, 1997) indicating a role in cell-mediated immunity. Deletion of $\mathrm{CX}_{3} \mathrm{CR} 1$ and inhibition of FKN function using neutralizing antibodies protects mice from allograft rejection (Haskell et al, 2001; Robinson et al, 2000). Moreover, FKN has been shown to play a role in amplifying Th1, or cell-mediated immunity responses (Fraticelli et al, 2001). Finally, Nishimura et al (2002) recently demonstrated that $\mathrm{CX}_{3} \mathrm{CR} 1$ expression defined a subpopulation of cytotoxic effector $\mathrm{CD}^{+} \mathrm{T}$ cells and natural killer cells, and that soluble FKN preferentially induced the migration of these subpopulations in vitro. Together, these data suggest that FKN plays an important role in cell-mediated immunity, and it may be to the advantage of invasive bacteria to actively inhibit soluble FKN production by fibroblasts in an attempt to disrupt the development of effective cytotoxic responses by the host. On the other hand, recent studies demonstrate that FKN inhibits Fas-dependent apoptosis of brain microglia (Boehme et al, 2000). If a similar mechanism exists in fibroblasts, it is possible that a host-defense mechanism is in operation, preventing fibroblasts from producing a chemokine that may inhibit cytotoxic responses against them when they are infected.

At this stage, we cannot provide a clear indication of the mechanism of inhibition of FKN expression by the invasive strain of $E$. coli. Multiple attempts to collect RNA from infected dermal fibroblasts failed to isolate RNA of sufficient quality to assess mRNA levels. However, our studies indicate that intracellular levels of FKN accumulating in response to TNF- $\alpha$ and IFN- $\gamma$ also are reduced by co-incubation with E. colinv (data not shown). This suggests that the inhibitory effect is at the level of transcription or translation rather than secretion or modulation of cleavage from the cell surface.

\section{Conclusion}

Our data demonstrate for the first time that dermal fibroblasts are able to express FKN in response to pro-inflammatory cytokines. FKN expression by these cells is predominantly of the soluble form and is delayed compared with the secretion of other chemokines. Exposure to bacteria does not activate FKN gene expression in dermal fibroblasts, and bacteria with an invasive phenotype inhibit inflammatory cytokine-induced FKN expression. Further studies will be required to elucidate the mechanism involved in this inhibition. The use of other genetically modified $E$. coli strains engineered to express known characteristics corresponding to specific microbial strains also should provide important and novel information regarding bacterial regulation of chemokine gene expression in these cells.

\section{Materials and Methods}

\section{Reagents}

Recombinant human cytokines, TNF- $\alpha$, IL-1 $\beta$, and IFN- $\gamma$, were a gift from Knoll Pharmaceuticals (Whippany, New Jersey) or were purchased from Genentech (San Francisco, California) and Prepro Tech (Rocky Hill, New Jersey), respectively. Goat $A b$ to human FKN, mAbs to human IL-8, MCP-1 and RANTES, and biotinylated goat Abs to human FKN, IL-8, and RAN- 
TES were obtained from R\&D Systems (Minneapolis, Minnesota). Rabbit anti-human MCP-1 was prepared and used as previously described (Hachicha et al, 1993). Peroxidase-conjugated streptavidin and peroxidase-conjugated donkey anti-rabbit antibody were purchased from Rockland (Gilbertsville, Pennsylvania). OPD peroxidase substrate was purchased from Sigma-Aldrich (Steinheim, Germany). Recombinant chemokines were a kind gift from Professor lan Clark-Lewis (University of British Colombia, Vancouver, Canada).

\section{Cell Culture and Bacterial Infection}

Primary human-dermal fibroblasts derived from foreskin were cultured in $75-\mathrm{cm}^{2}$ vented cap culture flasks in DMEM medium (Gibco, Auckland, New Zealand), supplemented with $10 \%$ heat-inactivated FCS, $2 \mathrm{~mm}$ of L-glutamine, penicillin, and gentamicin until confluence was reached. Before experiments, cells were treated with $0.05 \%$ trypsin and $0.53 \mathrm{~nm}$ of EDTA (Gibco), subcultured into 6-well, flat-bottomed, tissue culture plates (Becton Dickinson, Franklin Lakes, New Jersey), and allowed to settle for 24 hours to obtain a confluent monolayer. Fibroblasts then were washed once with sterile PBS before exposure to cytokines or bacteria.

Bacterial strains were obtained from the library of the Department of Molecular Biosciences at the University of Adelaide. Wild-type E. coli was grown in LB Broth medium, whereas the invasive $E$. coli strain was grown in LB Broth supplemented with $25 \mu \mathrm{g} / \mathrm{ml}$ of chloramphenicol. E. colinv was produced by transforming $E$. coli $i^{\text {wt }}$ with a plasmid encoding the $Y$. pseudotuberculosis invasin gene (Isberg et al, 1987; Rosenshine et al, 1992). The bacteria were harvested and washed twice in sterile DMEM and counted. The pellets were resuspended in sterile DMEM and various dilutions were added to the fibroblasts. The plates were spun for 10 minutes at 1500 rpm to allow quick settling of the bacteria on the cell surface and incubated for 1 hour. Fibroblasts then were washed once with sterile DMEM to remove nonadherent bacteria, and fresh medium supplemented with L-glutamine, penicillin, and gentamicin was added. For visualization of the infection, fibroblasts were treated as described earlier on Falcon culture slides (Becton Dickinson). Slides were washed once in PBS, fixed for 7 minutes in a solution of acetone:methanol (6:4), rinsed in sterile water, and air-dried. Cells then were stained with the DNA-specific fluorescent probe, DAPI, at $8 \mu \mathrm{m}$ for 1 minute, rinsed twice in sterile water, air-dried briefly, mounted in Mowiol medium, and visualized by fluorescence microscopy using an Olympus $\mathrm{BH} 2-\mathrm{RFCA}$ fluorescence microscope.

\section{Quantitation of Chemokine Levels}

Concentrations of FKN, IL-8, MCP-1, and RANTES were measured by ELISA as previously described (Hachicha et al, 1993), except that for the quantitation of FKN, the samples were concentrated 10-fold using a vacuum chamber. After removal of the cell supernatants, plates were placed on ice and cells were harvested mechanically in PBS supplemented with a protease-inhibitor cocktail (Roche Diagnostics, Mannheim, Germany). The cell-associated fraction was obtained by means of three consecutive freeze-thaw cycles. Cell debris was removed by centrifugation for 10 minutes at $14,000 \mathrm{rpm}$, and the supernatants were collected.

\section{RNA Extraction and RT-PCR}

Cells were resuspended in TRIzol (Life Technologies, Melbourne, Australia), and RNA was extracted according to the manufacturer's recommendations. RNA $(5 \mu \mathrm{g})$ was treated with DNase I (Promega, Madison, Wisconsin) and $2.5 \mu \mathrm{g}$ were used in first-strand cDNA synthesis, priming with oligo- $(\mathrm{dT})_{15}$ (Promega) and using the SuperScript II Pre-amplification system (Life Technologies). PCR was performed using AmpliTaq Gold (Perkin-Elmer, Foster City, California) following manufacturer's recommendations. The sequences of the forward and reverse primers were as follows: GAPDH, 5'-TCC TTG GAG GCC ATG TAG GCC AT-3' and 5'-TGA TGA CAT CAA GAA GGT GGT GAA G-3'; FKN, 5'-ATG GCT CCG ATA TCT CTG-3' and 5'-TGC TGC ATC GCG TCC TTG-3'. PCR cycling conditions were $94^{\circ} \mathrm{C}$ for 4 minutes, followed by repeated cycles of $94^{\circ} \mathrm{C}$ for 30 seconds, $65^{\circ} \mathrm{C}$ for 30 seconds, and $72^{\circ} \mathrm{C}$ for 30 seconds, followed by 7 -minute extension at $72^{\circ} \mathrm{C}$. The number of amplification cycles for each product was determined to define optimal conditions for linearity and to allow semiquantitative analysis of signal strength. Thirty-five cycles were performed for GAPDH, and 45 for FKN. Amplified PCR products were separated by gel electrophoresis on $2 \%$ agarose gels, stained with ethidium bromide, and visualized/ analyzed using a Molecular Imager FX (Bio-Rad, Hercules, California). The band-intensity values for FKN products were expressed as a ratio relative to band intensity for the GAPDH housekeeping gene PCR products amplified from the same template.

\section{Flow Cytometric Analysis}

For flow-cytometry experiments, cells were incubated with cytokines as described earlier, and with $50 \mu \mathrm{M}$ of hydroxamate inhibitor of matrix metalloproteinase (GM 6001; Biomol, Plymouth Meeting, Pennsylvania) for 48 hours. After removal of supernatants, fibroblasts were detached from culture plates using ice-cold PBS with $2 \mathrm{~mm}$ of EDTA and gentle scraping. Cells were resuspended in PBS containing $2 \%$ pooled human $A B$ serum (Red Cross, Adelaide, Australia) and 0.04\% sodium azide (staining buffer). Cells were incubated with anti-FKN Ab or goat IgG control, both at $10 \mu \mathrm{g} / \mathrm{ml}$ for 30 minutes on ice, washed with staining buffer, and then successively incubated for 30 minutes on ice with a biotinylated anti-goat $\mathrm{Ab}$ and phycoerythrinconjugated streptavidin (Rockland, Gilbertsville, Pennsylvania). After a final wash with serum-free staining buffer, cells were fixed in $300 \mu$ l of parafor- 
maldehyde (1\% in PBS). Labeled cells were detected using a Becton Dickinson FACScan (Mountain View, California), and data were analyzed using CellQuest 3.1 software.

\section{Statistical Analysis}

Unless otherwise stated, statistical analyses were performed using a two-tailed Student $t$ test. Values of $p<0.05$ were considered significant.

\section{Acknowledgements}

The authors thank Ann Hallett for the raising of antibodies against chemokines, Dinali Devasagayam for excellent technical assistance, and Sean Reilly for kindly providing primary human-dermal fibroblasts.

\section{References}

Bazan JF, Bacon KB, Hardiman G, Wang W, Soo K, Rossi D, Greaves DR, Zlotnik A, and Schall TJ (1997). A new class of membrane-bound chemokine with a CX3C motif. Nature 385:640-644.

Boehme SA, Lio FM, Maciejewski-Lenoir D, Bacon KB, and Conlon PJ (2000). The chemokine fractalkine inhibits Fasmediated cell death of brain microglia. J Immunol 165:397-403.

Fong AM, Robinson LA, Steeber DA, Tedder TF, Yoshie O, Imai T, and Patel DD (1998). Fractalkine and CX3CR1 mediate a novel mechanism of leukocyte capture, firm adhesion, and activation under physiologic flow. J Exp Med 188:14131419.

Fraticelli P, Sironi M, Bianchi G, D’Ambrosio D, Albanesi C, Stoppacciaro A, Chieppa M, Allavena P, Ruco L, Girolomoni G, Sinigaglia F, Vecchi A, and Mantovani A (2001). FractaIkine (CX3CL1) as an amplification circuit of polarized Th1 responses. J Clin Invest 107:1173-1181.

Gale LM and McColl SR (1999). Chemokines: Extracellular messengers for all occasions? Bioassays 21:17-28.

Gillitzer R and Goebeler M (2001). Chemokines in cutaneous wound healing. J Leukoc Biol 69:513-521.

Hachicha M, Rathanaswami P, Naccache PH, and McColl SR (1998). Regulation of chemokine gene expression in human peripheral blood neutrophils phagocytosing microbial pathogens. J Immunol 160:449-454.

Hachicha M, Rathanaswami P, Schall TJ, and McColl SR (1993). Production of monocyte chemotactic protein-1 in human type B synoviocytes. Synergistic effect of tumor necrosis factor alpha and interferon-gamma. Arthritis Rheum 36:26-34.

Haskell CA, Hancock WW, Salant DJ, Gao W, Csizmadia V, Peters W, Faia K, Fituri O, Rottman JB, and Charo IF (2001). Targeted deletion of CX(3)CR1 reveals a role for fractalkine in cardiac allograft rejection. J Clin Invest 108:679-688.

Imai T, Hieshima K, Haskell C, Baba M, Nagira M, Nishimura M, Kakizaki M, Takagi S, Nomiyama H, Schall TJ, and Yoshie O (1997). Identification and molecular characterization of fractalkine receptor CX3CR1, which mediates both leukocyte migration and adhesion. Cell 91:521-530.

Isberg RR, Voorhis DL, and Falkow S (1987). Identification of invasin: a protein that allows enteric bacteria to penetrate cultured mammalian cells. Cell 50:769-778.
Lucas AD, Chadwick N, Warren BF, Jewell DP, Gordon S, Powrie F, and Greaves DR (2001). The transmembrane form of the CX3CL1 chemokine fractalkine is expressed predominantly by epithelial cells in vivo. Am J Pathol 158:855-866.

Ludwig A, Berkhout T, Moores K, Groot P, and Chapman G (2002). Fractalkine is expressed by smooth muscle cells in response to IFN-gamma and TNF-alpha and is modulated by metalloproteinase activity. J Immunol 168:604-612.

Muehlhoefer A, Saubermann LJ, Gu X, Luedtke-Heckenkamp K, Xavier R, Blumberg RS, Podolsky DK, MacDermott RP, and Reinecker HC (2000). Fractalkine is an epithelial and endothelial cell-derived chemoattractant for intraepithelial lymphocytes in the small intestinal mucosa. J Immunol 164:3368-3376.

Nishimura M, Umehara H, Nakayama T, Yoneda O, Hieshima K, Kakizaki M, Dohmae N, Yoshie O, and Imai T (2002). Dual functions of fractalkine/CX3C ligand 1 in trafficking of perforin+/granzyme B+ cytotoxic effector lymphocytes that are defined by CX3CR1 expression. J Immunol 168:6173-6180.

Rathanaswami $P$, Hachicha M, Sadick M, Schall TJ, and McColl SR (1993a). Expression of the cytokine RANTES in human rheumatoid synovial fibroblasts. Differential regulation of RANTES and interleukin-8 genes by inflammatory cytokines. J Biol Chem 268:5834-5839.

Rathanaswami $\mathrm{P}$, Hachicha M, Wong $\mathrm{WL}$, Schall TJ, and McColl SR (1993b). Synergistic effect of interleukin-1 beta and tumor necrosis factor alpha on interleukin-8 gene expression in synovial fibroblasts. Evidence that interleukin- 8 is the major neutrophil-activating chemokine released in response to monokine activation. Arthritis Rheum 36:12951304.

Raychaudhuri SP, Jiang WY, and Farber EM (2001). Cellular localization of fractalkine at sites of inflammation: Antigenpresenting cells in psoriasis express high levels of fractalkine. Br J Dermatol 144:1105-1113.

Rennekampff HO, Hansbrough JF, Kiessig V, Dore C, Sticherling M, and Schroder JM (2000). Bioactive interleukin-8 is expressed in wounds and enhances wound healing. J Surg Res 93:41-54.

Robinson LA, Nataraj C, Thomas DW, Howell DN, Griffiths R, Bautch V, Patel DD, Feng L, and Coffman TM (2000). A role for fractalkine and its receptor (CX3CR1) in cardiac allograft rejection. J Immunol 165:6067-6072.

Rosenshine I, Duronio V, and Finlay BB (1992). Tyrosine protein kinase inhibitors block invasin-promoted bacterial uptake by epithelial cells. Infect Immun 60:2211-2217.

Tsou CL, Haskell CA, and Charo IF (2001). Tumor necrosis factor-alpha-converting enzyme mediates the inducible cleavage of fractalkine. J Biol Chem 276:44622-44626.

Tuschil A, Lam C, Haslberger A, and Lindley I (1992). Interleukin-8 stimulates calcium transients and promotes epidermal cell proliferation. J Invest Dermatol 99:294-298.

Volin MV, Woods JM, Amin MA, Connors MA, Harlow LA, and Koch AE (2001). Fractalkine: A novel angiogenic chemokine in rheumatoid arthritis. Am J Pathol 159:1521-1530.

Yoshida H, Imaizumi T, Fujimoto K, Matsuo N, Kimura K, Cui X, Matsumiya T, Tanji K, Shibata T, Tamo W, Kumagai M, and Satoh K (2001). Synergistic stimulation, by tumor necrosis factor-alpha and interferon-gamma, of fractalkine expression in human astrocytes. Neurosci Lett 303:132-136. 